\title{
Perspectives
}

\section{WHEN ORGANIZATIONAL JUSTICE ENACTMENT IS A ZERO \\ SUM GAME: A TRADE-OFF AND SELF-CONCEPT \\ MAINTENANCE PERSPECTIVE}

\begin{tabular}{|r|l|}
\hline Journal: & Academy of Management Perspectives \\
\hline Manuscript ID & AMP-2018-0003.R4 \\
\hline Document Type: & Article \\
\hline Keywords: & $\begin{array}{l}\text { Justice/fairness < Individual Level of Analysis < Organizational behavior } \\
<\text { Topic Areas, Leadership < Group/team processes < Group Level of } \\
\text { Analysis < Organizational behavior < Topic Areas, Decision-making < } \\
\text { Managerial and Organizational Cognition < Topic Areas, Cognition and } \\
\text { perception < Individual Level of Analysis < Organizational behavior }< \\
\text { Topic Areas }\end{array}$ \\
\hline
\end{tabular}

\section{SCHOLARONE \\ Manuscripts}


WHEN ORGANIZATIONAL JUSTICE ENACTMENT IS A ZERO SUM GAME:

A TRADE-OFF AND SELF-CONCEPT MAINTENANCE PERSPECTIVE

\author{
Jeroen Camps \\ Thomas More \\ jeroen.camps@thomasmore.be \\ Maja Graso \\ University of Otago \\ maja.graso@otago.ac.nz
}

Lieven Brebels

KU Leuven

lieven.brebels@kuleuven.be

\begin{abstract}
We would like to express our sincere gratitude to the editorial team and the reviewers for their guidance throughout the entire review process. Their constructive suggestions have greatly aided us in developing this manuscript. We would also like to thank Steven Grover for his helpful feedback on an earlier version of our paper proposal.
\end{abstract}




\begin{abstract}
A cliché portrayal of justice is one of a blindfolded entity wielding scales on which the merit of each party's case is weighted. In this article, we raise the idea that there are visible circumstances in which tipping of these symbolic scales can indicate not only this classic representation of substantiated evidence favoring one potential outcome over another, but also a brutal reality in which justice enactment for one can represent injustice for the other. We outline that justice often is a finite resource, and that justice enactment is the result of trade-off decision-making that is guided by self-concept maintenance strivings. We discuss three trade-offs to showcase our perspective: 1) distributing goods as a function of agents' ideological beliefs, 2) enacting justice for one party over the other as a function of contemporary moral culture, and 3) enacting justice within the boundaries of time. Each time, we propose how justice agents could balance the desire to maintain a positive self-view as fair and impartial with the unconscious drive to protect self-relevant beliefs and convictions. This helps them to protect viewing themselves as just and fair to all involved, while in fact rendering justice for some at the expense of justice for others. Our perspective aims to spur the debate on justice enactment as a finite resource, involving trade-offs and self-concept maintenance.
\end{abstract}

Keywords: justice, justice enactment, trade-offs, self-concept maintenance 
Pretty, isn't it? Perfectly balanced, as all things should be.

Thanos, Avengers: Infinity War

Decades of research identified justice as an invaluable resource for employees, organizations, and their customers (Cohen-Charash \& Spector, 2001; Colquitt, 2001; Colquitt, Conlon, Wesson, Porter, \& Ng, 2001; Colquitt et al., 2013). Studies contributing to our understanding of antecedents and consequences of organizational justice are now neatly summarized for academic audiences (see Ambrose, Wo, \& Griffith, 2015), and they are prepackaged and made applicable for practitioners (Cropanzano, Bowen, \& Gilliland, 2007). As the icing on the cake, the most recent wave in the justice literature is explicitly aimed at understanding factors that can help or impede its enactment in the workplace (for a recent review of this literature, see Graso, Camps, Strah, \& Brebels, in press). When pushed to the extreme, however, the corresponding onus on managers to enact fair procedures can contribute to the misleading idea that the enactment of justice is a process that can be optimized as long as we adhere to justice principles.

Yet, if this were true and if we, as a field, are so well-informed and knowledgeable in the ways of fair treatment as the breadth of justice literature would suggest that we should be, why do we continue to observe workplace injustices? The cynics among us can argue that we are inadvertently hoarding our academic knowledge, or that we are unable to effectively connect with practitioners by failing to present our findings in a way that is useful to them. Neither of those arguments, however, has merit (see Bies, 2012; Brockner, 2006; Cropanzano et al., 2007). In this contribution, we propose a more nuanced answer to the question why 
agents $^{1}$ often fail to acknowledge that their often well-intended decisions render injustice, harm, or negative consequences for some of the parties involved.

The prevailing implicit view that justice enactment can be maximized as long as certain practices are upheld is perhaps a remnant of the dominant perspective in the targetfocused literature oriented at identifying which actions increase justice perceptions (Barclay, Bashshur, \& Fortin, 2017; Bianchi \& Brockner, 2012; Brockner, Wiesenfeld, Siegel, Bobocel, \& Liu, 2015). For instance, it has even been argued that understanding how agents' personality relates to the presence of justice climates allows organizations to ensure that they "select and/or promote the kinds of leaders who are capable of creating fair climates where most, if not all, members perceive fair treatment" (Mayer, Nishii, Schneider, \& Goldstein, 2007, p. 953). We contrast this view with an image that dates back to the very roots of legal scholarship: a clichéd, yet fitting portrayal of justice as a blindfolded divine entity wielding scales on which the merit of each party's case is weighed. After a careful consideration of the competing interests and arguments of the parties involved, Lady Justice renders an unbiased trade-off in order to ensure that justice is served. Contrary to this deity passing impartial judgments, however, is human decision-making; a process that is sloppy, bounded by various limitations, and is often far from the neutral, cold rationality that this entity so visibly embodies (Gigerenzer \& Gaissmaier, 2011; Kahneman, 2003; Kunda, 1987). We make our case that this perspective, in which justice enactment involves the reconciliation of multiple interests (e.g., Feather, 1999), has been underrepresented in the justice enactment literature to date. Rather than being something that can be maximized, we argue that justice-related decisions involve trade-offs that are often unanticipated, unrecognized or unacknowledged due to the way human cognition works.

\footnotetext{
${ }^{1}$ By justice agents, we refer to those individuals who have decision-making power to make justice-based decisions (e.g., managers, human resource professionals, those who have power to serve on the court of public opinion and organizational leadership).
} 
Our aim is to extend the dominant discourse in the justice enactment literature by incorporating the perspective that justice agents engage in trade-off decision-making similar to this blindfolded deity, yet at the same time are bound by their own self-concept when doing so, due to the limits that come with human nature. Specifically, when justice agents are faced with a trade-off decision, they will - guided by the values, preferences, and convictions that are nested in their self-concept - favor one potential decision over another. As a result, the justice they enact will represent a finite - rather than an infinite - resource as any decision will bring justice for some and injustice for others ${ }^{2}$. Yet, if agents so often engage in trade-off decision-making as we argue, why is it that they then fail to acknowledge that their wellintended decisions render injustice for some of the parties involved?

We direct this discourse to a robust line of research that documents the pull of psychological mechanisms helping individuals to maintain a rosy, optimistic, and positive view of themselves (Brockner, Wiesenfeld, \& Diekmann, 2009; Heine, Lehman, Markus, \& Kitayama, 1999; Mazar, Amir, \& Ariely, 2008; Mezulis, Abramson, Hyde, \& Hankin, 2004). Along with these positivity-preserving force field shielding one against damages to their ego, of notable interest to us is the self-concept maintenance theory (Mazar et al., 2008). This theory specifies that individuals' drive to maintain a positive self-view will prevail even in face of one's own dishonesty. Because of those self-protective influences, agents will be unable to fully recognize the severity, impact, and reach of their decisions (see also Brockner et al, 2009). Moreover, guided by this lack of awareness regarding their own trade-off decision-making, agents can maintain the genuine belief that they acted in a fair and just manner.

\footnotetext{
${ }^{2}$ Our discourse that justice enactment often involves trade-offs, bringing justice for some and injustice for others, should not be confused with the notion of outcome favorability (i.e., favorable outcomes for some and unfavorable outcomes for others). Outcome favorability refers to whether someone receives the outcome they prefer or not (Skitka, Winquist, \& Hutchinson, 2003). Our focus goes beyond preferences or narrowly defined quid pro quo exchanges as we reflect on the very foundation of what people see as just and unjust. Specifically, we argue that people's sense of justice is rooted within their self-concept.
} 
For example, consider a fictional Supreme Court judge whose values and beliefs are strongly rooted in the Catholic faith and who is required to rule on an amendment to the abortion law. Despite this judge's sincere intent to objectively weigh the merits of a more flexible abortion law against the merits of a more conservative one, his decision is prone to be guided by his Catholic beliefs, depicting that all human life is sacred. After careful consideration, he decides to rule in favor of a more conservative abortion law. While either decision would have brought justice for some and injustice for others, self-concept maintenance theory (Mazar et al., 2008) explains how this judge might categorize his tradeoff decision as a decision that merely enabled him to protect those without a voice (i.e., those unborn) or as a decision that safeguards women from making a mistake that they might regret the rest of their lives, thereby allowing him to maintain the genuine belief that he ensured justice for all.

This speculation corresponds with well-documented findings that demonstrate how managers often see their actions as fairer than their direct reports see them (Brockner, 2006; Cropanzano et al., 2007). However, by emphasizing trade-offs and self-concept maintenance, we challenge the current view that fairness perceptions will be augmented when managers understand the principles of justice and are motivated to adhere to them. The main focus is on the unintended or unconscious violations of justice in the workplace that underpin these trade-offs, even at maximum levels of awareness and motivation to enact those principles. The prevalence of such unconscious or subtle violations has been noted (e.g., Graso et al., in press; Scott, Garza, Conlon, \& Kim, 2014; Whiteside \& Barclay, 2016, 2018), but our understanding of them remains limited and has been guided by an emphasis on the idea that, as a practice, justice enactment can be maximized in most circumstances.

By contemplating the possibilities of this perspective, we aim to make two contributions to this literature. First, research on justice enactment has identified both 
situational factors (e.g., Monin, Noorderhaven, Vaara, \& Kroon, 2013; Sherf, Venkataramani, \& Gajendran, in press; Wo, Ambrose, \& Schminke, 2015) and individual factors (e.g., Brebels, De Cremer, van Dijke, \& Van Hiel, 2011; Patient \& Skarlicki, 2010; Qin, Ren, Zhang, \& Johnson, 2017; Scott et al., 2014; Wolfe, Nix, \& Campbell, 2018) that guide agents' behavior. Despite the fact that these findings may help us better understand justice violations, we maintain that they will not entirely eliminate them because trade-offs between competing interests are inherent to many justice-related decisions. To initiate a genuine conversation on this matter, we identify three specific, yet diverse contexts in which potential trade-offs are likely to occur. We chose one trade-off that can be traced back to the roots of the organizational justice literature (i.e., distributing goods as a function of agents' ideological beliefs), one trade-off that captures the complexity of the current culture that prioritizes harm-avoidance (Campbell \& Manning, 2014, 2018; Lukianoff \& Haidt, 2015, 2018) and the corresponding social context in which justice enactment occurs (i.e., enacting justice for one party over the other), and a final trade-off that touches upon a long-neglected, yet crucial facet of justice-infused decision-making (i.e., enacting justice within the boundaries of time). Each of these trade-offs has unique implications for justice enactment and each covers a rather wide scope of inquiry. These multifaceted examples will allow us to initiate a conversation and inspire a potential path forward in this field.

Second, we aim to contribute to the existing justice enactment literature by advancing the conversation on 'bounded justice enactment', and thus furthering the exciting arguments on roadblocks to justice enactment (Ambrose \& Schminke, 2009) and bounded rationality (Kahneman, 2003) in general. We do so by examining the role of the self in situations in which justice is a finite resource and its enactment is a zero-sum game. We draw on selfconcept maintenance theory (Mazar et al., 2008) to argue that agents tend to resolve such 
justice trade-offs in a way that aligns with their self-concept, but only to the extent that it does not compromise viewing themselves as fair or moral for everyone.

We proceed as follows. First, we award closer attention to the universal human drive for positive self-regard and detail how it allows agents to genuinely believe that their decisions are fair to all involved. Second, we make our case by discussing the abovementioned trade-offs, provide examples and discuss how agents, guided by their selfconcept, weigh different interests against one another while maintaining a positive selfimage. Finally, we elaborate on the implications of this perspective for research on justice enactment.

\section{Universal Drive for Positive Self-Regard: From Justice Recipients to Justice Agents}

The idea that recipients' appraisal of and reactions to justice events are closely intertwined with and guided by their self-concepts is well documented and widely accepted (Brebels, De Crember, \& van Dijke, 2014; Clayton \& Optotow, 2003; Holmvall \& Bobocel, 2008; Johnson, Selenta, \& Lord, 2006). In fact, in their recent integrative contingency model of justice reasoning, Skitka, Aramovich, Lytle, and Sargis (2010, p. 22) even noted:

"How people define and think about fairness is stored in close connections to different aspects of the self and self-related goal systems in memory, and therefore are differentially likely to be activated or accessible as a function of which aspect of the self currently dominates the perceivers' working self-concept."

The justice enactment literature so far appears more optimistic about the human capacity to disentangle between what is seen as fair and the self. Some caution is warranted, however, as agents have decision power over others in justice-sensitive situations and empirical evidence highlights that feeling powerful increases an orientation toward the self (Galinsky, Magee, Inesi, \& Gruenfeld, 2006). Given this power, it is reasonable to expect that 
justice agents are even more likely than recipients to be guided by their ideologies, convictions, and interests when they reason about justice. At the same time, however, just as leaders are in general concerned with self-presentation (e.g., Gardner \& Avolio, 1998; Sosik, Avolio, \& Jung, 2002), we can expect that justice agents will be similarly constrained by their strong desire to maintain a positive self-view and reputation as being fair (Brockner et al., 2009). This duality aligns well with other recent accounts that emphasize how power can both undermine and elevate morality (Lammers, Galinsky, Dubois, \& Rucker, 2015).

Despite the image of impartial justice agents who strive to optimize justice enactment, we challenge the prevailing implicit assumption that justice is an infinite resource that agents can safely use to deliberately create win-win situations. After all, justice enactment can have rather unanticipated and even negative consequences (see Johnson, Lanaj, \& Barnes, 2014; Zapata, Carton, \& Liu, 2016), further casting doubt on the narrative that it is a uniformly positive phenomenon. We argue that agents' efforts to increase justice through their actions are often guided by self-concept maintenance strivings (Mazar et al., 2008), making them blind to the unintended injustice that their justice enactment brings. Mazar and colleagues (2008) developed this theory to account for observations that when provided with opportunities to cheat, people look for ways to balance their motivation to gain from dishonesty with the competing motivation to maintain a positive self-view as being honest. Extending positivity bias (Heine et al., 1999; Mezulis et al., 2004) and specifically selfconcept maintenance theory (Mazar et al., 2008) to organizational justice enactment, we propose that justice agents balance a strong desire to maintain a positive view of themselves as fair and impartial with the unconscious drive to protect their own beliefs and convictions while resolving justice trade-offs. After all, as is the case for any human decision maker, agents' beliefs, values, and goals are likely to consciously or unconsciously guide the choices they make when they engage in trade-off decision-making (Custers \& Aarts, 2010). 
Self-relevant cognitive processing will allow justice agents to maintain their positive self-image of being fair, neutral, and impartial in most circumstances. Specifically, people generally underestimate the extent to which they engage in cognitive processing that helps them to see the benefits of their own choices (i.e., subjective optimization) once they are made and have become unchangeable (Antonovsky, 1987; Gilbert \& Ebert, 2002). This psychological immune system may similarly allow justice agents to focus on the justice they installed for some and neglect the justice violations they brought upon others, thereby lowering the awareness that an actual trade-off has been made and allowing the maintenance of a positive self-regard in which justice for all is served.

\section{Trade-offs in Justice Enactment}

The underpinnings of our perspective imply that in certain situations, the trade-offs that justice agents face will result in justice enactment being a zero-sum game; victory for one will come at direct detriment of another. Of course, organizational justice researchers have not shied away from the concept of trade-offs, as some of the seminal pieces acknowledge that in order to enact fair decisions, weighing the merits of multiple recipients and taking into consideration resource limitations are crucial steps (e.g., Ambrose \& Schminke, 2009; Elliott \& Meeker, 1986; Feather, 1999; Margolis \& Molinsky, 2008; Scott, Colquitt, \& Paddock, 2009). However, those vantage points tend to focus on justice situations in which agents are at least aware of the potential difficulties and dilemmas they are facing while trying to be fair (e.g., delivering bad news; Margolis \& Molinsky, 2008). Relatedly, we do not focus on situations where agents need to determine whether being more fair is actually preferred (Brockner et al., 2009) or where they need to weigh objective against subjective fairness (for a discussion on potential trade-offs between enhancing validity and optimizing perceived fairness in employee selection see van Dijke \& De Cremer, 2016). In contrast, our focus is on a somewhat different vantage point - when agents are unaware of the 
consequences of their actions and when they do not recognize the impact on some of the parties involved (see Whiteside \& Barclay, 2016, 2018).

We selected three trade-offs that we believe are particularly well positioned to obscure agents' vision, and allow them to walk out of a trade-off-imbued situation sincerely believing that they have enacted justice for all involved: 1) distributing goods as a function of agents' ideological beliefs, 2) enacting justice for one party over the other as a function of contemporary moral culture, and 3) enacting justice within the boundaries of time. Of course, just like we argue that justice agents' decisions are guided by the values, preferences, and convictions that are central to their self, it is likely that our choice of trade-off contexts and our justification for them is grounded in our own self-concepts and influenced by our own perceptual limitations. We therefore do not aim to provide an exhaustive list of potential trade-offs, but we merely aspire to ignite debate amongst scholars, advocating for granting the self a more central role in studies on justice enactment and the trade-offs it involves.

\section{Trade-off \#1: Distributing Goods as a Function of Agents' Ideological Beliefs}

We commence our discussion of possible trade-offs that justice agents face by going back to the basics and reminiscing of the early days of organizational justice. In the longstanding tradition of research in this area, distributive justice was the first principle that received scholarly attention (Greenberg, 1990) and is one is most clearly relevant for discussing the idea that agents are faced with trade-offs. Strongly rooted in equity theory (Adams, 1965), distributive justice is often regarded as representing the extent to which a person's outcomes are in accordance with his or her contributions. Simply put, enacting distributive justice would mean distributing outcomes (e.g., pay, training opportunities, holiday rights, or promotion opportunities) in such a manner that each employee gets what they presumably deserve. 
Dilemma of distributive justice. Given the seemingly clear nature of this principle, it might appear unlikely that decision-makers are faced with trade-offs when they strive to enact distributive justice. Yet, rather than suggesting that the enactment of distributive justice does not involve trade-offs, another explanation might be that scholarly work has taken a rather one-sided approach that has remained overly focussed on the equity principle in studying distributive justice (see Rupp, Shapiro, Folger, Skarlicki, \& Shao, 2017 for a critique of this issue). This focus leads us to neglect the fact that outcomes can come in many forms (Törnblom \& Kazemi, 2015), they can be allocated according to many different principles and that trade-offs between competing principles are likely to occur. Rupp and colleagues (2017, p. 928) rightfully pinpoint to this limitation in the contemporary management literature as they make the following observation:

“...nearly all contemporary treatments of distributive justice consider outcomes to be fair when they have been distributed equitably. As reviewed earlier, equity is but one of multiple distribution rules or allocation principles that can be applied (or expected) in the spirit of fairness (Deutsch, 1975; Lerner, 1977; Reiss, 1986).”

Indeed, seminal theorizing on justice (Deutsch, 1975; Leventhal, 1976) already emphasized that distributive justice and the equity principle are not one and the same. While adhering to the equity principle can certainly aid justice agents to enact distributive justice, other principles for distributing goods are equally relevant to consider, and can even become of primary concern for some recipients in specific situations (Eek, Biel, \& Gärling, 2001). Deutsch (1975) made a case for two principles in addition to the equity principle: equality and need. The principle of equality dictates that valuable resources or favourable outcomes should be distributed equally amongst employees. The principle of need suggests that those resources should not be allocated roughly equally amongst employees or based on merit, but rather based on the extent to which an employee needs the specific outcome that is being 
distributed. For example, Cropanzano and colleagues (2007, p.37) state that "there is more to distributive justice than simple equity" and that these "different standards can be in conflict with one another." These words of caution issued by some of the foremost justice thinkers should certainly inspire us as a field to consider that justice agents often need to make tradeoffs between these different principles when enacting distributive justice.

Consider, for example, the way training opportunities are distributed in organizations. When outlining training policies, human resource development managers are faced with different possibilities to allocate these opportunities amongst their staff (Grugulis, 2000; Hocquet, 1999; Nordhaug, 1989). For example, in accordance with the equity principle, they could decide to offer the most desirable training opportunities to high-performing employees as a means reward good performance. Or, following the need principle, training opportunities can be mainly reserved for those employees who lack required skills and need to improve their performance. Yet, another approach would be to offer equal training opportunities to all employees of the organization, regardless of their level of performance or need for skill development.

Though highly simplified, this example shows how real and difficult decisions that involve trade-offs can be. However, for managers who are contemplating these choices and are wondering whether the most or least skilled employees are worthy of training, we can assume that they are at least making this choice consciously with some awareness of the fact that their decision is a difficult one. Organizations may even be implementing those distribution principles as a way of motivation and to meet a specific organizational goal (e.g., Monin et al., 2013). They may strive to improve morale or foster harmony (i.e., through enacting equality), and once the first goal is achieved and morale is improved, they might turn to fostering competition instead. Such utility of different distribution systems was fittingly illustrated by Monin and colleagues (2013). In contrast, our argument extends 
beyond this simple overview of distribution principles. We argue that regardless of the benefits and downsides of each possible decision, justice agents are likely to have a preferred approach that they will implement, and at the same time, they will be able to maintain a view of themselves as fair to all or most who are involved.

Distributive justice trade-offs at work: Ideology. Consider the crux of our first trade-off, the ever-contentious realms of religion and political ideologies. To describe the power of our own beliefs in maintaining the positive self-concept, Jonathan Haidt proclaims that "we are all self-righteous hypocrites" - seemingly good people, yet divided by our own convictions (Haidt, 2013, p. xvi). Our righteousness, in turn, allows us to go through life convinced we are, in fact, doing good. We believe that justice agents' self-concept might be a useful explanation in this case. Specifically, political ideology, an essential component of an individual's self-concept (Mazar et al., 2008), is known to heavily shape one's attitudes, ideas, and helps them make sense out of their social environment (Jost, Federico, \& Napier, 2009). Essential to our discourse on justice agents, it also helps individuals either legitimize the system that aligns with their ideologies, or react against the one that does not. We contemplate that agents of organizational justice will make trade-offs based on their ideological leanings, which, consistent with our self-concept and trade-off approach to justice enactment, will prevent them from seeing how their actions are perceived by those who view the world through a different ideological lens.

One of the most pronounced dimensions of these ideologies lie in the individual differences in social dominance orientation, which in part reflects the extent to which individuals endorse egalitarianism and cultural elitism (Pratto, Sidanius, Stallworth, \& Malle, 1994). Both of these outlooks deal closely with reward distributions: Should we award the bonuses only to top performers or should we give an equal share to all? Should we admit students to universities based exclusively on merit, or should we consider individuals' 
socioeconomic or ethnic backgrounds and acknowledge the possibilities of having an unequal start in life? Should we allow high earners to keep their earnings, or should we expect them to distribute their wealth to those less fortunate? A reader's endorsement of the first option in those three scenarios would suggest a rather elitist view of the world in which merit and competence reign as supreme values, whereas loosely endorsing the second option would reflect an ethos that society is bettered through promoting equality of all.

At the global levels, egalitarianism and the corresponding attitudes, practices, and systems that are aimed at reducing inequality have been hailed as some of the most ambitious and worthy of contemporary ideals, as evidenced by the latter's recognition as one of the 17 Sustainable Development Goals set forth by the United Nations in 2015. Therefore, hardly anybody would now look with disdain a decision-maker who designs and implements organizational systems that are in sync with these widely espoused values of social equality. In contrast, the idea that elitism and its practices can be unfair is widely supported and its criticisms tend to be more tolerated by the public court of opinion. For example, protesters frequently lament the unjust ways of being in which the top $1 \%$ holds the majority of the world's resources, and scholars have not yet tired themselves from documenting the ills of elitist practices, particularly for those least fortunate. Nonetheless, remaining faithful to our theme that justice can be a zero-sum game, we use emerging research to propose that the ethicality of distributions systems is complex, and that those designed around elitism, but also egalitarianism, can lead to injustice.

For example, Zhu, Aquino, and Vadera (2016) rely on literature on motivated reasoning to demonstrate that both egalitarian and elitist proponents tend to engage in motivated cognition to legitimize the existing system. They assessed participants' reactions to professors of varying status cues (e.g., race, gender, caste, and their university affiliation). Elitists, naturally predisposed to value status and social order, tend to show preference and 
award higher credibility to high-, rather than a low-status professor. Their egalitarian counterparts in turn evaluate low-status professors as more credible that those of high-status (Zhu et al., 2016). Similarly, a recent meta-analysis suggested the presence of biases in broader ideologies. Specifically, Ditto et al. (2018) demonstrated that both liberals and conservatives tend to engage in bias and motivated cognition in favour of their own party, making them consistently more likely to be less sceptical of information that aligns with their own political views, rather than opposes them.

In order to illustrate the implications of the latter phenomenon where egalitarianism leads to injustice and has unintended consequences, we turn to a recent example of biases in the university admissions process. Harvard, among other well-known universities recently came under public scrutiny after it was revealed that its admission processes are biased against Asian Americans (Lee \& Kumashiro, 2018; Wong, 2018). In comparison to other demographic groups, Asian Americans have consistently received lower marks on personality traits such as likability, integrity, helpfulness, and courage, although they tend to have the highest academic scores. This “Asian-American penalty" cost coveted admission spots of numerous Asian teenagers, and if removed, the estimates suggest that their acceptance rate would increase from $5.2 \%$ to $19.2 \%$ (Wong, 2018).

The role of agents' self-concept maintenance and the difficulties of trade-offs become apparent if we analyse this case. The quest for upholding values of equality has certainly benefitted students from impoverished backgrounds, but this benefit came at the expense of well-performing Asian Americans. In other words, an agent making such a decision could very well retain the image of being fair by upholding egalitarian principles as they give students from impoverished backgrounds a chance to study at such an esteemed university. However, perhaps they were not aware of the extent to which their decisions negatively impact those who would benefit from having more elitists on the admissions board. It is well 
beyond the scope of our article to engage in intricate assessments of both points and counterpoints of this complex case or to critique the metrics used to determine a holistic worth of a person, and we recognize that employing both meritocratic and egalitarian principles in this case has merit (e.g., Fang, 2018). Therefore, elitism, but also egalitarianism could bring direct justice for some and injustice for others. This case allows us to provide a broad illustration of an instance in which an individual's attitudes, beliefs, and other components of self-concept elitism, corroborate and lead to convictions in which self-concept is maintained.

\section{Trade-off \#2: Enacting Justice for One Party over the Other as a Function of}

\section{Contemporary Moral Culture}

The foundational tenet upon which our different trade-off sections are based is that people in general are motivated to retain a positive view of themselves (Heine et al., 1999; Mezulis et al., 2004) and they seek to maintain a strong and favorable self-concept even in instances of their own dishonesty and moral failings (Mazar et al., 2008). We maintain that for justice agents, one of the best, most salient, and most effective way to maintain a positive self-concept is to view themselves as moral (i.e., have high moral identity; Aquino \& Reed, 2002; Boegershausen, Aquino, \& Reed, 2015) and position themselves as agents for good. Justice and morality have long shared a mutually complementary and fruitful history (Ambrose \& Schminke, 2009; Rest, 1986), and morality remains one of the central components of organizational justice (Leventhal, 1980). It would therefore stand to reason that when attempting to design holistically positive workplace environments, practices involved with enactment of justice and morality could be viewed as interchangeable. There is, however, a dilemma. Morality is multi-faceted (e.g., Graham, Haidt, \& Nosek, 2009; Haidt, 2003; Haidt \& Graham, 2007; Schein \& Gray, 2016; Schein \& Gray, 2018), malleable (Nucci \& Turiel, 1978; Rozin, 1999; Turiel, 1989; Turiel, Killen, \& Helwig, 1987), and its 
pendulum can often be steered to reflect the different preferences of the populace at any given time due to a variety of contextual factors (Campbell \& Manning, 2014).

Of particular relevance to our core argument is the contemporary interplay between two essential components of moral foundations: the idea that people are vulnerable and have the right to be protected, versus the idea that people have the right to receive certain kinds of treatment (Haidt \& Graham, 2007). Thinkers have argued that the current culture in many Western countries is one that views the former values of care for the vulnerable, harmavoidance, and safety as morally superior ideals (Campbell \& Manning, 2014, 2018; Lukianoff \& Haidt, 2015, 2018). In fact, we observe that this prioritization of ensuring safety for those who are deemed vulnerable can even come at the expense of the right to receive appropriate treatment for those who are deemed to threaten this sense for safety.

These changes in societal moral pulse might present a true challenge for agents who wish to view themselves as moral protectors of all involved, as they will need to weight their desires to safeguard the rights of (alleged) harm-doers against the societal emphasis on harmavoidance for (potential) victims. These considerations will ultimately require them to make trade-offs in situations in which both parties' rights need to be taken into account, but justice for one party can only prevail at the detriment of justice for the other. We certainly do not argue that the two are mutually exclusive in all cases, so we limit our focus to those instances in which making decisions that protect those who may be exposed to harm and that ensure a proper treatment for all involved are, indeed, a zero-sum game. We elaborate on this contentious perspective by first discussing how the existing cultural values safeguard those who are exposed to harm over ensuring the rights of those who have potentially violated others' sense of safety. Next, we explain how trade-offs based on this interplay of cultural values impacts the recipients of fair or safe treatment. 
Shift towards the culture of psychological safety. The current socio-political climate in many Western countries (e.g., countries of North America and Western Europe) has propelled the matters pertaining to safeguarding those who are being harmed and protecting the rights of those who have contributed to such harm to the forefront of various discussions on social and organizational practices (Campbell \& Manning, 2014, 2018; Lukianoff \& Haidt, 2015, 2018). Consider, for example, the most salient, most widely discussed, and arguably most influential of recent movements: \#metoo. This movement itself started soon after a substantial wave of allegations of sexual assault flooded the entertainment industry. The champions of this movement, who were mostly women, wanted to express their outrage and frustration at the contemporary workplaces, in which they perceived that sexual harassment against their sisters is rampant. Allegations appended with \#metoo, \#timesup, or \#BalanceTonPorc ('out your pig' in French) reflected a range of behaviours that women found to be not only tasteless or inappropriate, but also dangerous and harmful to their physical or mental well-being. It is evident that at the core of this movement lies women's goal to seek care, safety, and to reduce harm (Women's March, 2018; Fetters, 2017).

The desire to seek safety and avoid harm is not limited only to women, thus further supporting the idea that the Western cultures might be embracing harm-avoidance (Campbell \& Manning, 2018) or safetysm (Lukianoff \& Haidt, 2018) as paramount values. Members of minority groups, such as LGBT+ individuals, African Americans, and those of different religious affiliations, have all engaged in similar endeavours to be granted the same level of physical, emotional, or psychological safety that is granted to other groups. The Black Lives Matter movement (\#BLM) emerged precisely because members of the African American community simply did not feel safe in their daily interactions with police. As the final piece of evidence supporting the idea that we live in a culture that emphasizes safety, consider the recent emergence of safe spaces and trigger warnings, which intend to help individuals who 
have suffered trauma feel safe, avoid distress, and prevent them from experiencing additional harm (Jackson, 2016; Levinovitz, 2016; Lukianoff \& Haidt, 2015).

\section{De-emphasizing the importance of appropriate treatment for (potential) harm-}

doers. While both protecting people against harmful incidents and ensuring appropriate treatment for all human beings have been clearly identified as fundamental components of morality (Gilligan \& Attanucci, 1994; Haidt \& Graham, 2007), there is emerging evidence that clearly deprioritizes or even delegitimizes the rights of harm-doers - potential or alleged - for due process, in favour of psychological safety and harm-prevention (Lukianoff \& Haidt, 2018). This is evident in several areas. For example, legal scholars are voicing their opinions and suggesting that the current infrastructure set to process sexual assault allegations on college campuses is deeply flawed and actively suppresses the defendant's right to due process (Kendall, 2018; Konradi, 2016; Safko, 2016). Rebuttals to their claims (e.g., Emba, 2017; Lapidus \& Park, 2018) often attenuate the threat to due process, while focusing on safety of the victim.

Consider, however, a more nuanced case in which the rights of offenders and the safety of victims are pinned against each other, yielding no single outcome that can appease both parties: the policy of Academy of Management (AOM) towards sexual harassment. Currently, this policy states that AOM will review sexual harassment complaints if the behaviour occurs during an AOM function (e.g., during an Academy conference session or an Academy-sponsored event) and the harassment is reported within six months. However, some view this policy to be overly restrictive for the actual victims of harassment, and are informally considering lifting of the reporting limit from six months to seven years, and for making the policy applicable beyond AOM functions to any professional setting ${ }^{3}$. As \#metoo

\footnotetext{
3 This issue was under informal, verbal discussion among Academy of Management members during the Academy of Management annual meeting in Chicago, 2018. The exact names and context in which the discussion occurred will not be revealed in order to protect AOM members' anonymity. However, similar
} 
retains its momentum to rid the workplaces of harassers, we envision that these adjustments would certainly be welcomed by a wider AOM membership, as they would provide an additional layer of protection for victims of harassment who might often be failed by the imperfect and bureaucracy-bound processes at their own institutions, or who fear their careers will be compromised should they report a misconduct by a well-known scholar.

It is clear why such alterations to existing sexual harassment policies could help victims feel safer and step forward. As authors of this paper, we ourselves certainly appreciate such thoughtful efforts that are meant to encourage better and more effective outlets for reporting, given that victims of harassment at work often feel uncomfortable stepping forward (Bergman et al., 2002; Cortina \& Magley, 2003). And, if we were fully confident that such policy amendments would come without potential ramifications, we would wholeheartedly endorse them. However, we are not convinced that that there are no ramifications. Extending the reporting period and widening the judiciary power of AOM over any professional setting might certainly make it easier for the accusers to come forward, but it can also compromise the quality of this internal judiciary process and thereby the rights of alleged offenders. It might become more challenging for the accused to defend themselves against the claims, as evidence might fade with time and observers' recollections risk becoming unreliable (Bradfield, Wells, \& Olson, 2002).

Cases in which the sole evidence is reliant upon one employee's word against the other put investigators in a unique predicament (Meinert, 2017). An agent who punishes the alleged perpetrator based on such accusation violates principles of procedural justice (Leventhal, 1980) and best practices for workplace investigations (Meinert, 2017). After all, in the absence of conclusive evidence to support the accuser's claim, any verdict resulting 
from such decision could be viewed as an affront to justice for the alleged perpetrator. A case where the accused employee is actually innocent and where the agent sides with the victim without providing the employee an opportunity to explain themselves, strongly represents the triumph of safeguarding those who are vulnerable over ensuring appropriate treatment for all involved. An alternative course of action would be to determine that the organization is unable to confidently bring forth a verdict due to clear lack of sufficient evidence (Meinert, 2017; Wex, no date). In that case, this decision would represent a triumph of the rights of the alleged perpetrator. But, this triumph could come at the expense of safety if the alleged perpetrator was, indeed, guilty of misconduct. Depending on the actual nature of the misconduct in this general example, inaction following an accusation can be particularly devastating to the victim and detrimental to others in the company, as it would essentially signal that their employees' concerns are not taken seriously, thus further perpetuating the toxicity of organizational climate (Bergman et al., 2002).

A formidable challenge to this claim might also be to point out that as time passes by, it might become more challenging for the victims to step forward and defend themselves, too. We acknowledge this possibility and we agree with its merit. However, in the current political climate, the allegation itself can be sufficient to bring the public's attention to the accused and the observers do not need to wait for official investigation to reach conclusion before the alleged individual suffers negative consequences (see McKie, 2015; Robertson, 2018). In addition, beyond academia, employee contracts in the United States are typically atwill (NCSL, 2017), so the organization might find it easier, even legally safer, to simply terminate the accused's employment, than to inadvertently signal support of hostile work environment through inaction and risk a potential lawsuit. As a note of caution, however, recent research shows that reactions that are deemed to be disproportionate for the actual offense might backfire as they enhance third-parties' sympathy for the (alleged) offender 
(Sawaoka \& Monin, 2018). This suggests that organizations adopting this approach might suffer negative consequences if there is doubt amongst the other employees regarding the alleged perpetrator's guiltiness or if later on it would turn out that the alleged perpetrator is innocent after all.

In summary, when making decisions to enact justice, agents will need to consider the pull of the competing forces including culture and agents' desire to protect those who are vulnerable versus safeguard the rights of potential harm-doers. As agents wish to maintain a positive view of themselves and use their decisions to signal their moral standing to the world, we argued that the contemporary notions of morality and specifically the emphasis on safety could, and as we illustrated, do carry potential to overpower one's own drive to enact justice. We suggest that this emphasis on psychological safety will lead to justice agents experiencing a significant conflict when deciding who is worthy of justice. Similarly, but outside the scope of our discourse here, other factors such as agents' identification with certain social groups (Decety \& Cowell, 2014) and their past experiences with similar situations (Fortin, Cojuharenco, Patient, \& German, 2014) are likely to influence their tradeoff decision-making when enacting justice involving different parties. The outcome of weighing the rights of (potential) victims versus the rights of (potential) perpetrators is that the final decision will represent a trade-off that will require agents to answer a crucial question: will they enact justice for the perceived moral patient (i.e., the victim) or for the moral agent (i.e., the perpetrator)?

\section{Trade-off \#3: Enacting Justice within the Boundaries of Time}

We will end our discourse by highlighting an aspect that is highly relevant for our discussion of trade-offs in justice enactment, yet has often been neglected in the organizational sciences: the matter of time (Fortin, 2008; Shipp \& Cole, 2015). Despite its underrepresentation in research, the relevance of time seems to be indisputable when it comes 
to making fairness judgements (Chun, Brockner, \& De Cremer, 2018) or assessing justiceinfused situations (Fortin et al., 2014). In support of the pivotal role of time, studies have not only demonstrated that employees care about the timeliness of enacted procedures (Outlaw, Colquitt, Baer, \& Sessions, 2018), but also that employees' fairness assessment of specific decisions are prone to change due to the temporal nature of justice concerns. For example, research by Ambrose and Cropanzano (2003) revealed that procedural justice was highly important to those involved at the time that a job decision was made, while distributive justice mattered more (and procedural justice less) a year after the decision was made. Related to this, a focus on the future makes employees' concerns about distributive justice most salient, while a focus on the past or present makes concerns about interpersonal justice more salient (Cojuharenco, Patient, \& Bashshur, 2011). Relevant to our discourse on tradeoffs in justice enactment is the undeniable fact that time is a scarce, valued resource. Moreover, a crucial aspect of contemporary time management is making trade-offs, a notion that is inherently nested within this concept (Aeon \& Aguinis, 2017; Macan, 1994; Northcraft, Schmidt, \& Ashford, 2011). In this regard, Aeon and Aguinis (2017, p. 319) recently noted the following:

"Granted, most people would agree with the statements "time is finite" and "time should be budgeted like money," but not everyone actually conceives of time that way in daily life."

We concede with Aeon and Aguinis' (2017) observation on this matter and argue that justice agents similarly face trade-offs in justice enactment due to a variety of time concerns, yet they are often unaware of the time-related factors that unavoidably affect their enactment of justice. Specifically, we propose the influence of two time-based issues of consideration in justice enactment. The first factor is one that is more obvious to scholars of justice - it reflects the simple amount of time agents devote to the decision-making process underlying 
their decisions. In tandem with our discourse on self-maintenance, agents could recognize that justice decisions stemming from processes that are rushed and pressured are typically a result of a fewer cognitive resources than those that are made with a mind-set free of distractors (Brockner et al., 2009; Kahneman, 2003). Furthermore, while procedural justice is highly beneficial for organizations in the long run (Colquitt et al., 2013), enacting fair procedures comes at a cost for managers in the short run as it requires cognitive resources (Johnson et al., 2014). Therefore, in addition to the amount of time spend to enact justicerelevant decisions, a manager has to weigh avoiding short-term costs against maximizing expected long-term gains when deciding how they allocate their time (Bandura, 2001; Brockner et al., 2009).

Although managers often have to make prompt decisions that are actively decoupled from long term outcomes, other decisions involve a much broader time frame and impact (Ariely \& Zakay, 2001), forcing agents to decide between the short-term and long-term implication of their decisions. Let us provide a particularly visible and visceral example of this temporal trade-off and consequences that it may entail. In order to do so, we venture beyond management. Consider how governments decide their approach to handle messy and highly charged issues of war crimes and persecution of war criminals. Specifically, contrast the time-based trade-offs of two justice bodies: 1) Truth and Reconciliation Commission (TRC) of South Africa, and 2) Den Haag War Crimes Tribunal. The notable issue of interest to us is that both have employed different temporal approaches to handling the post-war tensions.

Following the end of apartheid in South Africa, the Human Rights Violations committee was tasked with investigating the victims' claims of widespread and grave violations of human rights during that time, while The Reparation and Rehabilitation Committee worked on assisting the victims and rehabilitating them back into the society 
(USIP, 1995). In addition to facilitating the peace process through aiding victims, perpetrators were also given opportunities for amnesty. This process is consistent with numerous other 'truth commissions' set in place to recognize the past and address atrocities committed under the regime (Gibson, 2002). This was handled by the Amnesty Committee, which offered the perpetrators of the conflict and those who committed atrocities the opportunity to step forward, make a statement admitting their role and responsibility in the conflict, issue an apology, and seek amnesty. Amnesty was granted if the committee determined that the applicant acted to support a political ideology, if the actions were proportionate and enacted during the apartheid era, and if the applicant had made a full disclosure of their involvement. Upon the conclusion of the process, 840 out of 7,112 applications were granted amnesty, meaning that those individuals could now walk free. Whether or not this is a fair decision by itself is well beyond our discussion. This decision would involve consideration of accountabilities, agencies, role of the former government, and the impossible task of deciding appropriate compensations for the war crimes committed (for a thorough discussion on fairness of amnesty in South Africa see Gibson, 2002). Nonetheless, granting amnesty following full disclosure and acknowledgment of responsibility was an element that made the restorative justice of South Africa fairly unique, and its implications become particularly apparent when contrasting these amnestybased practices against the Den Haag War Crimes Tribunal for the former countries of Yugoslavia. This court, while handling deeply divisive ethnic tensions that broadly parallel those of South Africa, did not offer an option of seeking amnesty for those who participated in warfare. Instead, the Tribunal followed a set of procedures for dealing with war crimes. An argument can be made that a major challenge of this approach is the time it takes to enact justice in a specific situation. However, while the agents are taking their time to enact highquality justice, holding trials of atrocities committed in the 1990s prevent those countries 
from moving on, with each subsequent trial triggering the ethnic tensions that initially lead to the war (for a recent case, see AP, 2017). In summary, the unintended trade-offs in this case involve deciding between enacting: 1) swift and short-term justice, but then potentially allowing the perpetrators to get away with their crimes far too easily, and 2) long-term justice process employing classic and rigorous criteria of organizational justice (e.g., Leventhal, 1980), but compromising the ability of the citizens to move on by preventing the process to heal.

The examples above demonstrate that time is a scarce resource that forces justice agents to weigh the benefits and costs of one decision against the benefits and costs of another. However, time-based justice trade-offs during which the agents are likely to maintain the belief that they are fair to all involved are evident even in tamer, organizational contexts. This becomes particularly evident when considering that individuals are found to differ in the extent that they consider future versus immediate consequences of their actions (i.e., consideration of future consequences (CFC); Strathman, Gleicher, Boninger, \& Edwards, 1994), which could explain why agents and recipients might often hold different views regarding which side of the scale should be favored. As a result, agents can enact justice as they make decisions that are perfectly in line with their concern for the future, even though these same decisions will be perceived as unjust by recipients with a different time perspective. Consider the markers of a manager who scores high in consideration of future consequences. They would likely endorse statements such as: "I think it is important to take warnings about negative outcomes seriously even if the negative outcome will not occur for many years" or "I think it is more important to perform a behavior with important distant consequences than a behavior with less-important immediate consequences", and they might disagree strongly with descriptors such as "I only act to satisfy immediate concerns, figuring that I will take care of future problems that may occur at a later date" and "since my day to 
day work has specific outcomes, it is clearly more important than behavior that has distant outcomes." The latter two items would be more vigorously endorsed by a manager who is low in consideration of future consequences (Strathman et al., 1994, p. 752).

Impact of $\mathrm{CFC}$ orientation can be rather subtle, leading individuals to prioritize different aspects of their performance over others, depending on their such efforts yield more immediate or more delayed outcomes (see Graso \& Probst, 2012). Similarly, CFC can have obvious implications on what agents deem as fair or unfair, and their corresponding actions. Our high CFC manager might be careful considering how each decision that she makes impacts the organizational bottom line or the employees' morale, encouraging her to perhaps approach justice rather differently from her low CFC counterpart, who might be more likely to focus on the immediate issues at hand, and perhaps disregard the impact of justice decisions later down the road. Though both managers made a trade-off between the short and long-term consequences involving justice enactment, they are both likely to genuinely believe that they enacted justice in the best possible way as the decision-making process and the outcome strongly align with the beliefs nested in their self.

While we believe that agents' dispositional temporal orientation can certainly be a valid antecedent to justice enactment and we invite efforts to study this relationship empirically, we also believe that the contextual saliency of environmental stimuli will additionally drive agents' behavior. As an example of this idea, Reilly, Souder, and Ranucci (2016) have recently noted how contextual factors such as an organization's governance structure, firm-level strategic planning and a firm's financial situation have the power to influence decision-makers' focus on the short or long-term in resource allocation processes. Most importantly, it should be clear that enactment of justice can take time and it can require extensive resources, depending on the topic, and thereby inevitably requires agents to make trade-offs when enacting justice (Brockner et al., 2009). Orientation towards the future, either 
from the dispositional (Strathman et al., 1994), cultural (Hofstede, 2001), or induced perspective (Peetz \& Strahan, 2009) remains a somewhat overlooked factor that could predict the time-related trade-offs agents make when enacting justice. Our goal was simply to start a conversation on this issue from a perspective of justice enactment. However, subsequent analyses could benefit from awarding closer attention at this potentially fruitful issue.

\section{General Discussion}

Do we maintain that managers can maximize justice in their work organizations and that motivating them to adhere more closely to justice principles will ensure justice for all parties involved? Or, do we instead accept that despite managers' best efforts, justice enactment often involves trade-offs in which providing justice for some actually means sacrificing justice for others? In this article, we clearly sided with the latter view, as hinted by emerging justice enactment research and backed by a discussion of situations that provide challenging justice trade-offs to agents. Our perspective aims to remind justice scholarship that justice enactment involves careful consideration of competing interests and arguments of the different parties involved. Moreover, unlike the clichéd portrayal of Lady Justice, we posit that justice agents are not blindfolded when resolving justice trade-offs and therefore are far less impartial in their enactment of justice. We directed this discourse to self-concept maintenance (Mazar et al., 2008) in justice enactment, a framework we believe to be promising in understanding how managers unintendedly or unconsciously balance their natural tendency to be driven by self-relevant convictions and ideologies, with the desire to maintain strongly held beliefs in their own fairness, neutrality, and impartiality.

Our discourse was based in part on the observed inconsistency between the widely accepted idea that recipients' reactions to justice events are severely stirred by their selfconcepts (Brebels et al., 2014; Clayton \& Optotow, 2003; Holmvall \& Bobocel, 2008; Johnson et al., 2006) on the one hand, and the much more limited attention devoted to 
managers' capability to disentangle between their self-concept and what is seen as fair on the other hand. In fact, the decision power that managers have over others in justice-sensitive situations likely triggers an even greater orientation toward the self among managers as agents, than among their subordinates as recipients (Galinsky et al., 2006). However, managers may also differ from employees in feeling particularly constrained by their strong desire to maintain a positive self-view and reputation as being fair, suggesting that the decision power of managers can both undermine and facilitate justice enactment (Lammers et al., 2015). Based on this reasoning, we proposed that justice agents' efforts to increase justice through their actions are often guided by self-concept maintenance strivings (Mazar et al., 2008), making them blind to the unintended injustice that their justice enactment brings.

We discussed three trade-offs and showcased our reasoning for each of them. Reality is, however, often far more complex and can involve multiple trade-offs simultaneously. For instance, many countries in the EU are working to update their retirement security systems to anticipate the consequences of their aging populations and workforce. In doing so, they have to trade short-term justice outcomes (e.g., adhering to or violating initial promises) with longterm justice consequences (e.g., ensuring or compromising a sustainable welfare for future generations), while simultaneously implying a "justice for whom" trade-off, where the rights of those close to their retirement are weighted against those who have just recently entered the job market.

We encourage justice scholars to generate and explicitly address other trade-offs that characterize justice enactment and explore other areas that help us further expand upon our understanding of justice enactment in trade-off situations. For example, an obvious, more applied trade-off that we did not address concerns human resource managers who need to hire a candidate for a leadership position and thereby weigh different personality profiles against one another. The fact that any score on a given personality trait comes with benefits and 
downsides is commonly known (Judge \& Long, 2012), rendering finding the ideal candidate rather unlikely. Illustrating this fact, Grant, Gino, and Hofmann (2011) revealed that that passive employees perform better when working for an extraverted leader, while proactive employees perform better when working for an introverted leader. As most teams consist of a combination of passive and proactive members, HR-managers face a trade-off when they are required to select a new leader for a given team: do they opt for a leader who promotes the performance of the proactive members or a leader who promotes the performance of the passive ones?

The likelihood that HR-managers will be guided by their own self-concept during this decision-making process should become apparent from the fact that plenty of research has investigated the so-called similar-to-me-effect (Rand \& Wexley, 1975). As shown in the previous example, the self-concept maintenance framework offers plenty of opportunities for further exploration in understanding how justice agents resolve trade-offs. For instance, one interesting line of inquiry has been concerned with examining cross-cultural manifestations in the structure of the self-concept, revealing that individuals across cultures are driven by a motivational primacy of the individual self over more interdependent selves (Gaertner et al., 2012). Moreover, related research revealed that the tendency to self-enhance - i.e., believing that one is better than average on traits or skills that are deemed normatively important - is not restricted to individualistic cultures, but actually generalizes to more collectivistic cultures (Sedikides, Gaertner, \& Toguchi, 2003). Other research has contested this view suggesting that self-enhancement is much less common in East Asian than in Western cultures, if present at all (Heine, 2005). However, in line with self-concept maintenance, Sedikides, Gaertner, and Vevea (2005) demonstrated that people in all cultures engage in self-enhancement, but that they do so in ways that are strategically sensitive to cultural contexts. 
We also encourage scholars to further explore the role of the self in justice enactment. The idea that justice agents rely on their self-concept in resolving justice trade-offs does not necessary imply that agents will be consistent in how they resolve justice trade-offs across time, people, or situations. Although research often conveniently conceptualizes and operationalizes the self as a single construct or experience, the self-concept is malleable and actually comprises of a multifaceted diversity of identities (Aquino \& Reed, 2002; Gaertner et al., 2012; Markus \& Kunda, 1986). As a result, different settings, contexts, or cultures may make different aspects of the self particularly salient, as such resulting in substantial variability in how a particular justice agent resolves a particular justice trade-off across time, situations, and beneficiaries (Sandel, 2009).

Furthermore, one unaddressed potential source of this within-person variance in justice enactment may be found in a combination of psychological licensing and self-concept maintenance in justice trade-offs. Psychological licensing theorizing suggests that people sometimes feel less inhibited to do bad after doing good (Miller \& Effron, 2010; Monin \& Miller, 2001). With respect to resolving justice trade-offs, this mechanism may facilitate a justice agent to sacrifice justice for a particular beneficiary after providing justice for the same beneficiary on a prior occasion, and subsequently maintain viewing themselves as fair. Together with the current notion that justice enactment in itself often requires making multiple trade-off decisions, it stands to reason that justice agents will often be inconsistent in their justice rule adherence or violation toward a particular (group of) recipient(s). Interestingly, another recent contribution highlights why such variability in justice enactment may have unexpected and undesirable side effects. In a lab experiment and a diary study, it was revealed that recipients experienced more physiological stress under conditions of sporadic fair treatment than under conditions of consistent unfair treatment by their supervisor (Matta, Scott, Colquitt, Koopman, \& Passantino, 2017). 
On a more positive note, scholars interested in finding ways to reduce unwanted variability in justice enactment and perceptions can also benefit from the conceptual and empirical richness of the self-literature. For instance, another recent line of work pointed to the importance of construal level abstractness in determining whether positive self-views with respect to morality or fairness can lead to either an increase (i.e., consistency) or a decrease (i.e., inconsistency) in subsequent strivings to do good (e.g., Conway \& Peetz, 2012; Vess, Arndt, \& Schlegel, 2011). Specifically, this work provided evidence for the idea that more abstract representations of the self (e.g., traits) are related to more consistent action, while more concrete representations of the self (e.g., actions) relate to more inconsistent action.

We have developed the argument that managers are not necessarily cognizant of the trade-offs they have to face when dealing with justice issues. The question that remains is how can we provide them with some meaningful direction on how to navigate these complex situations? Economic theory recommends dealing with trade-offs by avoiding actions that result in the greatest opportunity costs and instead opt for those actions that have the smallest opportunity costs. Applying this principle to our discourse postulates that agents need to determine the opportunity costs related to the trade-offs they face when enacting justice. One way to minimize such opportunity costs is to verify to what extent the potential decisions at hand align with the organization's values (Arieli, Sagiv, \& Roccas, in press). By opting for a decision that corresponds best with the organization's values and goals, justice agents should be able to minimize the potential costs in light of the organization's long-term goals when resolving the trade-offs they face. Likewise, instead of being unconsciously guided by their own ideological considerations and personal preferences when enacting justice, agents who are aware of the fact that they face trade-offs could actually consciously turn to their own values in order to resolve these trade-offs. Acting in line with one's values comes with a 
variety of positive consequences (Arieli et al., in press; Edwards \& Cable, 2009; KristofBrown, Zimmerman, \& Johnson, 2005) and can help to ensure consistency over time. Though agents' values and the values of their organization should be congruent in an ideal world, given the associated benefits (Edwards \& Cable, 2009), it is likely that agents will face situations where their own personal values do not match those of their organization. In such more complex situations it again comes down to resolving trade-offs: to what extent will agents prioritize their own values over those of their organization - or vice versa?

\section{Conclusion}

Rather than conveying to managers an idealistic image of enacting justice for all in an impartial and neutral manner, we offered a different discourse that allows us to accept the brutal reality that justice enactment often is a zero-sum game that requires making trade-offs between competing interests, thereby often installing justice for some and injustice for others. One way in which managers can deal with this reality is by developing a more realistic mindset about their own potential for inconsistency, and by developing greater awareness of the convictions and ideologies that are tied to their self-concept in varying contexts. Managers can then start disentangling those aspects of the self (e.g., convictions and ideologies) they would like to internalize. However, in line with our reasoning that each decision comes with benefits and downsides, agents can ultimately even decide to refrain from devoting any resources to actively resolve the trade-offs they face and instead opt for maintenance of their blissful ignorance. 


\section{References}

Adams, J. S. (1965). Inequity in social exchange. In L. Berkowitz (Ed.), Advances in experimental social psychology (pp. 267-299). New York, NY: Academic Press.

Aeon, B., \& Aguinis, H. (2017). It's about time: New perspectives and insights on time management. Academy of Management Perspectives, 31, 309-330.

Ambrose, M. L., \& Cropanzano, R. (2003). A longitudinal analysis of organizational fairness: An examination of reactions to tenure and promotion decisions. Journal of Applied Psychology, 88, 266-275.

Ambrose, M. L., \& Schminke, M. (2009). Assessing roadblocks to justice: A model of fair behavior in organizations. In J. J. Martocchio \& H. Liao (Eds.), Research in personnel and human resources management (Vol. 28, pp. 219-263): Emerald Group Publishing Limited.

Ambrose, M. L., Wo, D. X. H., \& Griffith, M. D. (2015). Overall justice: Past, present and future. In R. S. Cropanzano \& M. L. Ambrose (Eds.), The Oxford handbook of justice in the workplace (pp. 109-136). New York, NY: Oxford University Press.

Antonovsky, A. (1987). Unraveling the mystery of health: How people manage stress and stay well. San Francisco, CA, US: Jossey-Bass.

AP. (2017, November 29, 2017). 'I am not a war criminal,' convicted Bosnian Croat cries as he takes a fatal dose of poison. Retrieved from http://www.latimes.com/world/la-fgcroatia-slobadan-praljak-20171129-story.html

Aquino, K., \& Reed, A. (2002). The self-importance of moral identity. Journal of Personality and Social Psychology, 83, 1423-1440.

Arieli, S., Sagiv, L., \& Roccas, S. (in press). Values at work: The impact of personal values in organisations. Applied Psychology: An International Review. 
Ariely, D., \& Zakay, D. (2001). A timely account of the role of duration in decision making. Acta Psychologica, 108, 187-207.

Bandura, A. (2001). Social cognitive theory: An agentic perspective. Annual Review of Psychology, 52, 1-26.

Barclay, L. J., Bashshur, M. R., \& Fortin, M. (2017). Motivated cognition and fairness: Insights, integration, and creating a path forward. Journal of Applied Psychology, $102,867-889$.

Bergman, M. E., Langhout, R. D., Palmieri, P. A., Cortina, L. M., Fitzgerald, L. F., \& Fitzgerald, L. F. (2002). The (un)reasonableness of reporting: Antecedents and consequences of reporting sexual harassment. Journal of Applied Psychology, 87, $230-242$.

Bianchi, E. C., \& Brockner, J. (2012). In the eyes of the beholder? The role of dispositional trust in judgments of procedural and interactional fairness. Organizational Behavior and Human Decision Processes, 118, 46-59.

Bies, R. (2012, May 30, 2012). The 10 commandments for delivering bad news. Retrieved from https://www.forbes.com/sites/forbesleadershipforum/2012/05/30/10commandments-for-delivering-bad-news/ - 702f72b62169

Boegershausen, J., Aquino, K., \& Reed, A. (2015). Moral identity. Current Opinion in Psychology, 6, 162-166.

Bradfield, A. L., Wells, G. L., \& Olson, E. A. (2002). The damaging effect of confirming feedback on the relation between eyewitness certainty and identification accuracy. Journal of Applied Psychology, 87, 112-120.

Brebels, L., De Cremer, D., \& van Dijke, M. (2014). Using self-definition to predict the influence of procedural justice on organizational-, interpersonal-, and job/taskoriented citizenship behavior. Journal of Management, 40, 731-763. 
Brebels, L., De Cremer, D., van Dijke, M., \& Van Hiel, A. (2011). Fairness as social responsibility: A moral self-regulation account of procedural justice enactment. British Journal of Management, 22, S47-S58.

Brockner, J. (2006). Why it's so hard to be fair. Harvard Business Review, 84, 122-129.

Brockner, J., Wiesenfeld, B. M., \& Diekmann, K. A. (2009). Towards a "fairer" conception of process fairness: Why, when, and how more may not always be better than less. Academy of Management Annals, 3, 183-216.

Brockner, J., Wiesenfeld, B. M., Siegel, P. A., Bobocel, D. R., \& Liu, Z. (2015). Riding the fifth wave: Organizational justice as dependent variable. Research in Organizational Behavior, 35, 103-121.

Campbell, B., \& Manning, J. (2014). Microaggression and moral cultures. Comparative Sociology, 13, 692-726.

Campbell, B., \& Manning, J. (2018). The rise of victimhood culture: Microaggressions, safe spaces, and the new culture wars. New York, NY: Palgrave Macmillan.

Chun, J. S., Brockner, J., \& De Cremer, D. (2018). How temporal and social comparisons in performance evaluation affect fairness perceptions. Organizational Behavior and Human Decision Processes, 145, 1-15.

Clayton, S., \& Optotow, S. (2003). Justice and identity: Changing perspectives on what is fair. Personality and Social Psychology Review, 7, 298-310.

Cohen-Charash, Y., \& Spector, P. E. (2001). The role of justice in organizations: A metaanalysis. Organizational Behavior and Human Decision Processes, 86, 278-321.

Cojuharenco, I., Patient, D., \& Bashshur, M. R. (2011). Seeing the "forest" or the "trees" of organizational justice: Effects of temporal perspective on employee concerns about unfair treatment at work. Organizational Behavior and Human Decision Processes, $116,17-31$. 
Colquitt, J. (2001). On the dimensionality of organizational justice: A construct validation of a measure. Journal of Applied Psychology, 86, 386-400.

Colquitt, J. A., Conlon, D. E., Wesson, M. J., Porter, C. O. L. H., \& Ng, K. Y. (2001). Justice at the millennium: A meta-analytic review of 25 years of organizational justice research. Journal of Applied Psychology, 86, 425-445.

Colquitt, J. A., Scott, B. A., Rodell, J. B., Long, D. M., Zapata, C. P., Conlon, D. E., \& Wesson, M. J. (2013). Justice at the millennium, a decade later: A meta-analytic test of social exchange and affect-based perspectives. Journal of Applied Psychology, 98, 199-236.

Conway, P., \& Peetz, J. (2012). When does feeling moral actually make you a better person? Conceptual abstraction moderates whether past moral deeds motivate consistency or compensatory behavior. Personality and Social Psychology Bulletin, 38, 907-919.

Cortina, L. M., \& Magley, V. J. (2003). Raising voice, risking retaliation: Events following interpersonal mistreatment in the workplace. Journal of Occupational Health Psychology, 8, 247-265.

Cropanzano, R., Bowen, D. E., \& Gilliland, S. W. (2007). The management of organizational justice. Academy of Management Perspectives, 21, 34-48.

Custers, R., \& Aarts, H. (2010). The unconscious will: How the pursuit of goals operates outside of conscious awareness. Science, 329, 47-50.

Decety, J., \& Cowell, J. M. (2014). The complex relation between morality and empathy. Trends in Cognitive Sciences, 18, 337-339.

Deutsch, M. (1975). Equity, equality, and need: What determines which value will be used as the basis of distributive justice? Journal of Social Issues, 31, 137-149. 
Ditto, P. H., Liu, B. S., Clark, C. J., Wojcik, S. P., Chen, E. E., Grady, R. H., . . Z Zinger, J. F. (2018). At least bias is bipartisan: A meta-analytic comparison of partisan bias in liberals and conservatives. Perspectives on Psychological Science, 14, 273-291.

Edwards, J. R., \& Cable, D. M. (2009). The value of value congruence. Journal of Applied Psychology, 94, 654-677.

Eek, D., Biel, A., \& Gärling, T. (2001). Cooperation in asymmetric social dilemmas when equality is perceived as unfair. Journal of Applied Social Psychology, 31, 649-666.

Elliott, G. C., \& Meeker, B. F. (1986). Achieving fairness in the face of competing concerns: The different effects of individual and group characteristics. Journal of Personality and Social Psychology, 50, 754-760.

Emba, C. (2017). The 'due process' assault freak-out is a fever dream. Retrieved from https://www.washingtonpost.com/opinions/the-due-process-assault-freak-out-is-afever-dream/2017/12/01/8f14cd80-d6d5-11e7-a986d0a9770d9a3e_story.html?utm_term=.fb0cad60bb5d

Fang, K. (2018, July 12, 2018). I'm an activist for Asian Americans. I support affirmative action. Retrieved from https://www.washingtonpost.com/opinions/im-an-activist-forasian-americans-i-support-affirmative-action/2018/07/12/f637fb54-7e0a-11e8-b6604d0f9f0351f1_story.html?utm_term=.dc69d59a7d82

Feather. (1999). Judgments of deservingness: Studies in the psychology of justice and achievement. Personality and Social Psychology Review, 3, 86-107.

Fetters, A. (2017, January 22, 2017). The men at the women's march on Washington. Retrieved from https://www.gq.com/story/photos-men-at-the-womens-march-onwashington 
Fortin, M. (2008). Perspectives on organizational justice: Concept clarification, social context integration, time and links with morality. International Journal of Management Reviews, 10, 93-126.

Fortin, M., Cojuharenco, I., Patient, D., \& German, H. (2014). It is time for justice: How time changes what we know about justice judgments and justice effects. Journal of Organizational Behavior, 37, S30-S56.

Gaertner, L., Sedikides, C., Luke, M., O'Mara, E. M., Iuzzini, J., Jackson, L. E., . . Wu, Q. (2012). A motivational hierarchy within: Primacy of the individual self, relational self, or collective self? Journal of Experimental Social Psychology, 48, 997-1013.

Galinsky, A. D., Magee, J. C., Inesi, M. E., \& Gruenfeld, D. H. (2006). Power and perspectives not taken. Psychological Science, 17, 1068-1074.

Gardner, W. L., \& Avolio, B. J. (1998). The charismatic relationship: A dramaturgical perspective. Academy of Management Review, 23, 32-58.

Gibson, J. L. (2002). Truth, justice, and reconciliation: Judging the fairness of amnesty in south africa. American Journal of Political Science, 46, 540-556.

Gigerenzer, G., \& Gaissmaier, W. (2011). Heuristic decision making. Annual Review of Psychology, 62, 451-482.

Gilbert, D. T., \& Ebert, J. E. J. (2002). Decisions and revisions: The affective forecasting of changeable outcomes. Journal of Personality and Social Psychology, 82, 503-514.

Gilligan, C., \& Attanucci, J. (1994). Two moral orientations: Gender differences and similarities. In B. Puka (Ed.), Moral development: Caring voices and women's moral frames. New York, NY: Garland Publishing, Inc.

Graham, J., Haidt, J., \& Nosek, B. A. (2009). Liberals and conservatives rely on different sets of moral foundations. Journal of Personality and Social Psychology, 96, 1029-1046. 
Grant, A. M., Gino, F., \& Hofmann, D. A. (2011). Reversing the extraverted leadership advantage: The role of employee proactivity. Academy of Management Journal, 54, 528-550.

Graso, M., Camps, J., Strah, N., \& Brebels, L. (in press). Organizational justice enactment: An agent-focused review and path forward. Journal of Vocational Behavior.

Graso, M., \& Probst, T. (2012). The effect of consideration of future consequences on quality and quantity aspects of job performance. Journal of Applied Social Psychology, 42, $1335-1352$.

Greenberg, J. (1990). Organizational justice: Yesterday, today, and tomorrow. Journal of Management, 16, 399-432.

Grugulis, I. (2000). The Management NVQ: A critique of the myth of relevance. Journal of Vocational Education and Training, 52, 79-99.

Haidt, J. (2003). The moral emotions. In R. J. Davidson, K. R. Scherer, \& H. H. Goldsmith (Eds.), Handbook of affective sciences (pp. 852-870). Oxford: Oxford University Press.

Haidt, J. (2013). The righteous mind: Why good people are divided by politics and religion. New York, NY: Vintage Books.

Haidt, J., \& Graham, J. (2007). When morality opposes justice: Conservatives have moral intuitions that liberals may not recognize. Social Justice Research, 20, 98-116.

Heine, S. H., Lehman, D. R., Markus, H. R., \& Kitayama, S. (1999). Is there a universal need for positive self-regard? Psychological Review, 106, 766-794.

Heine, S. J. (2005). Where is the evidence for pancultural self-enhancement? A reply to sedikides, gaertner, and toguchi (2003). Journal of Personality and Social Psychology, 89, 531-538. 
Hocquet, L. (1999). Vocational training as a force for equality? Training opportunities and outcomes in France and Britain. International Journal of Manpower, 20, 231-255.

Hofstede, G. (2001). Culture's consequences: Comparing values, behaviors, institutions, and organizations across nations, 2nd edition: Sage Publications, Inc.

Holmvall, C. M., \& Bobocel, D. R. (2008). What fair procedures say about me: Selfconstruals and reactions to procedural fairness. Organizational Behavior and Human Decision Processes, 105, 147-168.

Jackson, A. (2016). The Yale administrator at the center of a debate about racism on campus has resigned. Retrieved from https://www.businessinsider.com.au/nicholaschristakis-resigned-yale-2016-5? $\mathrm{r}=\mathrm{US} \& \mathrm{IR}=\mathrm{T}$

Johnson, R. E., Lanaj, K., \& Barnes, C. M. (2014). The good and bad of being fair: Effects of procedural and interpersonal justice behaviors on regulatory resources. Journal of Applied Psychology, 99, 635-650.

Johnson, R. E., Selenta, C., \& Lord, R. G. (2006). When organizational justice and the selfconcept meet: Consequences for the organization and its members. Organizational Behavior and Human Decision Processes, 99, 175-201.

Jost, J. T., Federico, C. M., \& Napier, J. L. (2009). Political ideology: Its structure, functions, and elective affinities. Annual Review of Psychology, 60, 307-337.

Judge, T. A., \& Long, D. M. (2012). Individual differences in leadership. In D. V. Day \& J. Antonakis (Eds.), The nature of leadership. Thousand Oaks, CA: Sage Publications.

Kahneman, D. (2003). A perspective on judgment and choice: Mapping bounded rationality. American Psychologist, 58, 697-720.

Kendall, A. (2018). Maryland rent courts fail to protect human rights to due process and fair trials. Chance, 31, 21-28.

Konradi, A. (2016). Can justice be served on campus? Humanity \& Society, 41, 373-404. 
Kristof-Brown, A. L., Zimmerman, R. D., \& Johnson, E. C. (2005). Consequences of individuals' fit at work: A meta-analysis of person-job, person-organization, persongroup, and person-supervisor fit. Personnel Psychology, 58, 281-342.

Kunda, Z. (1987). Motivated inference: Self-serving generation and evaluation of causal theories. Journal of Personality and Social Psychology, 53, 636-647.

Lammers, J., Galinsky, A. D., Dubois, D., \& Rucker, D. D. (2015). Power and morality. Current Opinion in Psychology, 6, 15-19.

Lapidus, L., \& Park, S. (2018, February 15, 2018). The real meaning of due process in the \#metoo era. Retrieved from https://www.theatlantic.com/politics/archive/2018/02/due-process-metoo/553427/

Lee, S. J., \& Kumashiro, K. K. (2018, June 27, 2018). Bias against Asian-American students is real. Affirmative action isn't the problem. Retrieved from https://www.vox.com/the-big-idea/2018/6/27/17509140/admissions-biaspersonalities-harvard-affirmative-action

Lerner, M. J. (1977). The justice motive: Some hypotheses as to its origins and forms. Journal of Personality, 45, 1-52.

Leventhal, G. S. (1976). The distribution of rewards and resources in groups and organizations. In L. Berkowitz \& W. Walster (Eds.), Advances in experimental social psychology (Vol. 9, pp. 91-131). New York, NY: Academic Press.

Leventhal, G. S. (1980). What should be done with equity theory? In K. J. Gergen, M. S. Greenberg, \& R. H. Willis (Eds.), Social exchange (pp. 27-55). Boston, MA: Springer.

Levinovitz, A. (2016). How trigger warnings silence religious students. Retrieved from https://www.theatlantic.com/politics/archive/2016/08/silencing-religious-students-oncampus/497951/ 
Lukianoff, G., \& Haidt, J. (2015). The coddling of the American mind. Retrieved from https://www.theatlantic.com/magazine/archive/2015/09/the-coddling-of-the-american$\operatorname{mind} / 399356 /$

Lukianoff, G., \& Haidt, J. (2018). The coddling of the American mind: How good intentions and bad ideas are setting up a generation for failure. New York, NY: Penguin Press.

Macan, T. H. (1994). Time management: Test of a process model. Journal of Applied Psychology, 79, 381-391.

Margolis, J. D., \& Molinsky, A. (2008). Navigating the bind of necessary evils: Psychological engagement and the production ofinterpersonally sensitive behavior. Academy of Management Journal, 51, 847-872.

Markus, H., \& Kunda, Z. (1986). Stability and malleability of the self-concept. Journal of Personality and Social Psychology, 51, 858-866.

Matta, F. K., Scott, B. A., Colquitt, J. A., Koopman, J., \& Passantino, L. G. (2017). Is consistently unfair better than sporadically fair? An investigation of justice variability and stress. Academy of Management Journal, 60, 743-770.

Mayer, D., Nishii, L., Schneider, B., \& Goldstein, H. (2007). The precursors and products of justice climates: Group leader antecedents and employee attitudinal consequences. Personnel Psychology, 60, 929-963.

Mazar, N., Amir, O., \& Ariely, D. (2008). Dishonesty of honest people: A theory of selfconcept maintenance. Journal of Marketing Research, 45, 633-644.

McKie, R. (2015, June 13, 2015). Tim Hunt: 'I've been hung out to dry. They haven't even bothered to ask for my side of affairs. Retrieved from https://www.theguardian.com/science/2015/jun/13/tim-hunt-hung-out-to-dryinterview-mary-collins 
Meinert, D. (2017). How to conduct a workplace investigation. Retrieved from https://www.shrm.org/hr-today/news/hr-magazine/pages/1214-workplaceinvestigations.aspx

Mezulis, A. H., Abramson, L. Y., Hyde, J. S., \& Hankin, B. L. (2004). Is there a universal positivity bias in attributions? A meta-analytic review of individual, developmental, and cultural differences in the self-serving attributional bias. Psychological Bulletin, $130,711-747$.

Miller, D. T., \& Effron, D. (2010). Psychological license: When is it needed and how it functions. Advances in Experimental Social Psychology, 43, 117-157.

Monin, B., \& Miller, D. T. (2001). Moral credentials and the expression of prejudice. Journal of Personality and Social Psychology, 81, 33-43.

Monin, P., Noorderhaven, N., Vaara, E., \& Kroon, D. (2013). Giving sense to and making sense of justice in postmerger integration. Academy of Management Journal, 56, 256-284.

NCSL (2017). The at-will presumption and exceptions to the rule. National Conference of State Legislatures. Retrieved from http://www.ncsl.org/research/labor-andemployment/at-will-employment-overview.aspx

Nordhaug, O. (1989). Reward functions of personnel training. Human Relations, 42, 373388

Northcraft, G. B., Schmidt, A. M., \& Ashford, S. J. (2011). Feedback and the rationing of time and effort among competing tasks. Journal of Applied Psychology, 96, 10761086.

Nucci, L. P., \& Turiel, E. (1978). Social interactions and the development of social concepts in preschool children. Child Development, 49, 400-407. 
Outlaw, R., Colquitt, J. A., Baer, M. D., \& Sessions, H. (in press). How fair versus how long: An integrative theory-based examination of procedural justice and procedural timeliness. Personnel Psychology.

Patient, D. L., \& Skarlicki, D. P. (2010). Increasing interpersonal and informational justice when communicating negative news: The role of the manager's empathic concern and moral development. Journal of Management, 36, 555-578.

Peetz, J., \& Strahan, A. E. W. E. J. (2009). So far away: The role of subjective temporal distance to future goals in motivation and behavior. Social Cognition, 27, 475-495.

Pratto, F., Sidanius, J., Stallworth, L. M., \& Malle, B. F. (1994). Social dominance orientation: A personality variable predicting social and political attitudes. Journal of Personality and Social Psychology, 67, 741-763.

Qin, X., Ren, R., Zhang, Z.-X., \& Johnson, R. E. (2017). Considering self-interests and symbolism together: How instrumental and value-expressive motives interact to influence supervisors' justice behavior. Personnel Psychology, 71, 225-253.

Rand, T. M., \& Wexley, K. N. (1975). Demonstration of the effect, "similar to me," in simulated employment interviews. Psychological Reports, 36, 535-544.

Reilly, G., Souder, D., \& Ranucci, R. (2016). Time horizon of investments in the resource allocation process. Journal of Management, 42, 1169-1194.

Reiss, H. T. (1986). Levels of interest in the study of interpersonal justice. In H. W. Bierhoff, R. L. Cohen \& J. Greenberg (Eds.), Justice in social relations (pp. 187-226). New York, NY: Plenum

Rest, J. R. (1986). Moral development: Advances in research and theory. New York, NY: Praeger. 
Robertson, A. (2018, July 26, 2018). Former assistant professor wins retaliation claim against Columbia. Retrieved from https://www.nytimes.com/2018/07/26/nyregion/professorsexual-harassment-suit-columbia.html

Rozin, P. (1999). The process of moralization. Psychological Science, 10, 218-221.

Rupp, D. E., Shapiro, D. L., Folger, R., Skarlicki, D., \& Shao, R. (2017). A critical analysis of the conceptualization and measurement of "organizational justice": Is it time for reassessment? Academy of Management Annals, 11, 915-959.

Safko, E. D. (2016). Are campus sexual assault tribunals fair: The need for judicial review and additional due process protections in light of new case law. Fordham Law Review, 84, 2289-2333.

Sandel, M. J. (2009). Justice: What's the right thing to do? New York: Farrar, Straus and Giroux.

Sawaoka, T., \& Monin, B. (2018). The paradox of viral outrage. Psychological Science, 29, $1665-1678$.

Schein, C., \& Gray, K. (2016). Moralization and harmification: The dyadic loop explains how the innocuous becomes harmful and wrong. Psychological Inquiry, 27, 62-65.

Schein, C., \& Gray, K. (2018). The theory of dyadic morality: Reinventing moral judgment by redefining harm. Personality and Social Psychology Review, 22, 32-70.

Scott, B. A., Colquitt, J. A., \& Paddock, E. L. (2009). An actor-focused model of justice rule adherence and violation: The role of managerial motives and discretion. Journal of Applied Psychology, 94, 756-769.

Scott, B. A., Garza, A. S., Conlon, D. E., \& Kim, Y. J. (2014). Why do managers act fairly in the first place? A daily investigation of "hot" and "cold" motives and discretion. Academy of Management Journal, 57, 1571-1591. 
Sedikides, C., Gaertner, L., \& Toguchi, Y. (2003). Pancultural self-enhancement. Journal of Personality \& Social Psychology, 84, 60-79.

Sedikides, C., Gaertner, L., \& Vevea, J. L. (2005). Pancultural self-enhancement reloaded: A meta-analytic reply to Heine (2005). Journal of Personality and Social Psychology, $89,539-551$.

Sherf, E. N., Venkataramani, V., \& Gajendran, R. S. (in press). Too busy to be fair? The effect of managers' perceived workload on their core technical performance and justice rule adherence. Academy of Management Journal.

Shipp, A. J., \& Cole, M. S. (2015). Time in individual-level organizational studies: What is it, how is it used, and why isn't it exploited more often? Annual Review of Organizational Psychology and Organizational Behavior, 2, 237-260.

Skitka, L. J., Aramovich, N. P., Lytle, B. L., \& Sargis, E. G. (2010). Knitting together an elephant: An integrative approach to understanding the psychology of justice reasoning. In D. R. Bobocel, K. A. C; Z. M. P;, O. J. M;, \& E. M. Mara (Eds.), The psychology of justice and legitimacy: The Ontario Symposium (11th volume). Philadelphia, PA: Psychology Press.

Skitka, L. J., Winquist, J., \& Hutchinson, S. (2003). Are outcome fairness and outcome favorability distinguishable psychological constructs? A meta-analytic review. Social Justice Research, 16, 309-341.

Sosik, J. J., Avolio, B. J., \& Jung, D. I. (2002). Beneath the mask: Examining the relationship of self-presentation attributes and impression management to charismatic leadership. The Leadership Quarterly, 13, 217-242.

SPSP (2019). SPSP sexual harassment survey results. Retrieved from http://www.spsp.org/announcements/sexual-harassment-survey 
Strathman, A., Gleicher, F., Boninger, D. S., \& Edwards, C. S. (1994). The consideration of future consequences: Weighing immediate and distant outcomes of behavior. Journal of Personality and Social Psychology, 66, 742-752.

Törnblom, K. Y., \& Kazemi, A. (2015). Distributive justice: Revisiting past statements and reflecting on future prospects. In R. S. Cropanzano \& M. L. Ambrose (Eds.), The Oxford handbook of justice in work organizations. Oxford: Oxford University Press.

Turiel, E. (1989). Domain-specific social judgments and domain ambiguities. Merrill-Palmer Quarterly, 35, 89-114.

Turiel, E., Killen, M., \& Helwig, C. C. (1987). Morality: Its structure, functions, and vagatires. In J. Kagan \& S. Lamb (Eds.), The emergence of morality in young children (pp. 155-243). Chicago, IL: University of Chicago Press.

USIP. (1995, 2018). Truth commission: South Africa. Retrieved from https://www.usip.org/publications/1995/12/truth-commission-south-africa

van Dijke, M., \& De Cremer, D. (2016). Justice in the work setting. In C. Sabbagh \& M. Schmitt (Eds.), Handbook of social justice theory and research (pp. 315-332). New York, NY: Springer Science + Business Media.

Vess, M., Arndt, J., \& Schlegel, R. J. (2011). Abstract construal levels attenuate state selfesteem reactivity. Journal of Experimental Social Psychology, 47, 861-864.

Wex (no date). Wex. Cornell Law School: Legal Information Institute. Retrieved from https://www.law.cornell.edu/wex/preponderance_of_the_evidence

Whiteside, D. B., \& Barclay, L. J. (2016). The face of fairness: Self-awareness as a means to promote fairness among managers with low empathy. Journal of Business Ethics, $137,721-730$. 
Whiteside, D. B., \& Barclay, L. J. (2018). When wanting to be fair is not enough: The effects of depletion and self-appraisal gaps on fair behavior. Journal of Management, 44, 3311-3335.

Wo, D. X. H., Ambrose, M. L., \& Schminke, M. (2015). What drives trickle-down effects? A test of multiple mediation processes. Academy of Management Journal, 58, 18481868.

Wolfe, S. E., Nix, J., \& Campbell, B. A. (2018). Police managers' self-control and support for organizational justice. Law and Human Behavior, 42, 71-82.

Women's march. (2018). Retrieved from https://www.womensmarch.com/mission/

Wong, A. (2018, June 19, 2018). Harvard's impossible personality test. Retrieved from https://www.theatlantic.com/education/archive/2018/06/harvard-admissionspersonality/563198/

Zapata, C. P., Carton, A. M., \& Liu, J. T. (2016). When justice promotes injustice: Why minority leaders experience bias when they adhere to interpersonal justice rules. Academy of Management Journal, 59, 1150-1173.

Zhu, L. L., Aquino, K., \& Vadera, A. K. (2016). What makes professors appear credible: The effect of demographic characteristics and ideological beliefs. Journal of Applied Psychology, 101, 862-880. 
Jeroen Camps (jeroen.camps@thomasmore.be) is a lecturer in organizational behavior and HRM at Thomas More and a research fellow at KU Leuven. He obtained his Ph.D. from KU Leuven (Topic: abusive supervision \& followership). His research focuses on organizational justice, leadership and followership.

Maja Graso (maja.graso@otago.ac.nz) is a senior lecturer in management at University of Otago in New Zealand. Prior to her current post, she spent five years teaching in the United Arab Emirates. Her current academic interests include organizational justice, behavioral ethics, and victimhood culture.

Lieven Brebels (lieven.brebels@,kuleuven.be) is an associate professor of leadership and organizational behavior at KU Leuven, Belgium. He obtained his Ph.D. from Tilburg University in The Netherlands (Topic: procedural justice as an evaluative and regulatory looking glass self). His research focuses on the self-concept in organizational justice and behavioral ethics. 